\section{Restoring good manners}

SIR - John Maddox asks how good manners can be restored to science (Nature 376, 113; 1995). He suggests that editors should act as better custodians of scientific virtue and that institutions and grant-making agencies also have responsibility in this arena. But the real problem is that science is bad-mannered by its nature. All of us want to be first, and push and shove to get there. And, should someone beat us to it, we delight in showing that they were wrong in detail if not necessarily in fact. This is healthy. Good, lasting, verifiable and useful science is made by the aggressive promulgation of ideas honed by the also-rans. No runners, no race.

But all is not so simple and Maddox is right to complain. Scientists do seem to be misbehaving to the extent that only a proportion of the vast literature now seems worth reading. And Maddox is largely correct in his targets. It is, however, journals and grant-makers that are principally contributing to the degradation of science. Vanity co-publication is a nuisance but is used by only a tiny minority to camouflage outright fraud. The total collapse of peer review within journals and by grant-making organizations is a far more serious threat to our common pursuit. Despite the fact that there are arguably more scientists extant than ever before, journals and grant-making bodies appear to ask ever fewer individuals to review their material for them. Their excuse may be inundation but the reason is laziness.

The journal I co-edit has a policy of varying its reviewers on the grounds that peer review should be regarded as little more than a market-research exercise, as I have mentioned in these pages and elsewhere before (Nature 364, 183; 1993 \& Redox Report 1, 1-2; 1994). This is more work for us but ensures that we get a wide range of opinion, which we then evaluate. By contrast, it must be the experience of many senior scientists that they are constantly landed with submitted articles or grant applications on a particular theme. "Old Joel understands this stuff. Send it to him" seems to be the attitude. But this means that O.J. effectively controls the field. And O.J. may have gone bonkers in the decade since he last held a pipette or be simply allergic to certain schools of thought so the field stagnates.

Entrusting the right to authorship or allocation of funds to a few individuals also, of course, contributes heavily to feelings of unfairness and suspicions of patronage. The characters are too easily

\section{Correspondence}

Letters submitted for Correspondence should be typed, double-spaced, on one side of the paper only. identifiable and their prejudices too well known. The simplest way to identify the range of scientists capable of reviewing an application or paper is to use electronic search methods combined with a letter, fax, e-mail or telephone call. Yes, this does involve more work and potential delay. Yes, this may mean transcribing incomprehensible foreign addresses with lots of consonants run together. Yes, this may mean asking the opinions of researchers who do not have English as their first language and who "don't know our system", but the results, and benefit to science, would make it worthwhile.

Simon P. Wolff

(Editor, Redox Report)

University College London

Medical School,

Rayne Institute,

5 University Street,

London WC1 6J, UK

\section{Benefits of dumping?}

SIR - As a microbiologist, I rejoiced at E. G. Nisbet's and C. M. R. Fowler's Commentary on the beneficial effects of dumping the Brent Spar oil storage platform to the deep-sea microbial flora and can only share their disappointment that it was eventually cancelled (Nature 375, 715; 1995). As the father of two children, I also know too well what these microbes must have felt about their missing Christmas gifts (Nature 375, 708; 1995). However, life goes on, and there are plenty of gifts for which we should be grateful.

We should welcome controlled and accidental release of nuclear fission products in the oceans and elsewhere which, by their mutagenic virtues, provide our microbial friends with a rich spectrum of adaptive perspectives. Similarly, sites of waste disposal are populated by myriads of rapidly evolving microbial species just waiting for tomorrow's new plastics. Wouldn't it be heartless not to give them what they need? On the basis of the arguments published in Nature, a solemn proposal should be issued by the scientific community to the Austrian. Swiss and German governments to dump a number of scrap cars in Lake Konstanz (which is also full of microbes but more easily accessible to the average microbiologist than the deep sea). I am ready to join Shell Oil in its ecological efforts and would generously donate my old Volkswagen for this purpose.

Rupert Mutzel

Universität Konstanz,

Postfach 5560,

D-78434 Konstanz, Germany

\section{Fair's fair}

SIR - Michael Lardelli (Nature 376, 123; 1995) expresses concern about a rule of the Human Frontier Science Program (HFSP) that the principal applicant for a research grant "must be a national of one of the eligible countries". Thus nationals of non-eligible countries, even if their laboratory is established in an eligible country, cannot be principal applicants.

HFSP was created on the initiative of the Japanese government in the framework of the Economic Summit; the eligible member countries are Canada, France, Germany, Italy, Japan, the United Kingdom, the United States, the other countries of the European Union and Switzerland. These countries fund the programme and the eligibility rule has been adopted as a fair requirement by the funding governments.

It should be emphasized, however, that this eligibility requirement applies only to the principal applicants, and that all other co-applicants can be of any nationality, eligible or not, provided that their laboratories are in two or more different countries. The purpose of the grants is to promote international collaboration. It is hardly restrictive when only one of the applicants must be from one of the 19 eligible countries.

\section{Michel Cuénod}

(Secretary General)

Human Frontier Science Program,

20 place des Halles,

76080 Strasbourg, France

\section{Rampant paranoia}

SIR - Robert Shields claims (Nature 374, $683 ; 1995)$ that one can "look in any journal of plant physiology [and find that $\mathrm{Ara}$ bidopsis] hardly rates a mention". This is an absurd statement; the mentioning of Arabidopsis in Plant Physiology - certainly a typical "journal of plant physiology" - is in fact excessive. The index to volume 103 (September-December 1993, one issue per month; the most recent volume in my office) lists 17 articles about Arabidopsis thaliana., and other articles in that volume also discuss $A$. thaliana. But it gets worse: one of the four issue covers of volume 103 of Plant Physiology highlights Arabidopsis. And, one of the other issue covers compares a tobacco gene to a gene of, that's right, Arabidopsis. To be fair, I checked the index to volume 102 (May-August 1993) and found, once again, 17 entries under $A$. thaliana

Shields is clearly suffering from "they don't talk about Arabidopsis enough" paranoia, and you are helping to spread the disorder.

Jeff Amthor

5107 Norma Way, Apt 31

Livermore, California 94550-3772, USA 